$\mathbb{T}$ periodica polytechnica

\author{
Civil Engineering \\ 58/4 (2014) 379,386 \\ doi: 10.3311/PPci.7507 \\ http://periodicapolytechnica.org/ci \\ Creative Commons Attribution (1) \\ RESEARCH ARTICLE
}

\section{Sensitivity analysis of GSI based mechanical parameters of the rock mass}

Péter Ván / Balázs Vásárhelyi

Received 2014-04-30, revised 2014-07-07, accepted 2014-08-26

\begin{abstract}
The purpose of this paper is to analyze the sensitivity of the various constants of the different mechanical equations that depend on the Geological Strength Index (GSI) and the disturbance factor (D). Recently, both the Hoek-Brown failure criteria and the Hoek-Diederichs equations for determining the rock mass moduli are widely used in rock mechanics. For calculation these parameters, it is necessary to determine both the Geological Strength Index (GSI) and the disturbance factor $(D)$. The results show that these parameters are very sensitive to both the GSI and the D factor, hence determining both them exactly is very important for the rock engineering design. Our results present the relationship between the uncertainties of GS I and D values and the uncertainties of the rock mass moduli. In order to establish good empirical formulas one should have some idea about the effect of variations in the input parameters for judging the acceptability of the design.
\end{abstract}

\section{Keywords}

sensitivity analysis $\cdot$ Geological Strength Index $\cdot$ disturbance factor $\cdot$ mechanical parameters

\section{Péter Ván}

Dept. of Theoretical Physics, Wigner RCP, of the HAS and Dept. of Energy Engineering, BME and Montavid Thermodynamic Research Group, Budapest, Hungary

\section{Balázs Vásárhelyi}

Dept. of Structural Engng., Pollack Mihály Faculty of Engng., Univ. of Pécs, Boszorkány út 2, H-7624, Pécs, Hungary

e-mail: vasarhelyib@gmail.com

\section{Introduction}

The sensitivity of various empirical formulas to parameter uncertainty is important for a rock engineering designer. The purpose of this paper is to determine the sensitivity of the different mechanical equations based on the Geological Strength Index $(G S I)$ and disturbance factor $(D)$. Bieniawski [1] demonstrates the high sensitivity of the Hoek-Brown failure criteria according to the results of Malkowski [2]: he shows that changing the GSI value by 5 , from 35 to 40 , leads to a dramatic increase in values of the following parameters: $\sigma_{c m}$ by $37 \%, m_{b}$ by $20 \%$ and in the modulus of deformation $E_{M}$ by $33 \%$, while that of parameter $s$ by $85 \%$ (see Eq. 11) and the accompanying explanation of these parameters).

It has to be noted that the origin of all of these GSI based equations is empirical, they do not have any theoretical foundation. Moreover, their empirical foundation is questionable, it was never published, as it was pointed out by Anagnostou and Pimentel [3]. Here we do not want to criticize the GSI system, nor the particular Hoek-Brown failure criteria, however, as it is frequently applied in engineering calculations, one should have some idea about the effect of variations in the input parameters for judging the acceptability of the design. Accordingly, we analyze the generalized Hoek-Brown formula from this point of view, and give some practical tools for rapid sensitivity analyses. The first steps of this analysis were carried out by Ván and Vásárhelyi [4,5].

\section{Geological Strength Index (GSI) and the disturbance factor $(D)$}

The Geological Strength Index (GSI), as a system of rock mass characterization, was introduced by Hoek [6-8] and recently it is widely used in rock engineering designs (in Hungary see [9]). The goal of this engineering geological system was to present input data, particularly those related to rock mass properties, required as inputs into numerical analysis or closed form solutions for designing tunnels, slopes or foundations in or on rocks. It provides a field method so the geological character of rock material, together with the visual assessment of the mass it forms, is used as a direct input to the selection of parameters 
relevant for the prediction of various mechanical properties of the rock mass. This approach enables a rock mass to be considered as a mechanical continuum. Marinos et al. [10] review the application and the limitation of the Geological Strength In$\operatorname{dex}(G S I)$, showing the determination methods. However, it is well known that the determination of this parameter is not easy and is not exact; it is encumbered by several uncertainties. On Fig. 1 the general chart for GS I determination is presented following Marinos and Hoek [11]. According to the original definition, "From the lithology, structure and surface conditions of the discontinuities, estimate the average value of GSI. Do not try to be too precise. Quoting a range from 33 to 37 is more realistic than stating that $G S I=35$ " $[10]$. Therefore, in relative terms, the GSI here is $35 \pm 10 \%$ and because the exactness is given in absolute terms, for lower values the relative error increases. This is what is suggested using GSI in case of very weak and sheared rock masses, i.e. flysch and schist, where GS I $<30$ [8, 12]. E.g. if the $G S I=10(8<G S I<12)$ the sensitivity of this value reaches $20 \%$ !

Sen and Barton [13] accentuated the importance of the block volume. The GS I value, according to its definition, does not depend on the block volume, which is a very important property of the rock mass. Therefore, if the discontinuity conditions are unchanged, rock mass formed by cubical blocks of $1 \mathrm{~cm}^{3}$ will have the same $G S I$ as the one formed by blocks of $1 \mathrm{dm}^{3}$, or even of $1 \mathrm{~m}^{3}$. In order to eliminate this problem, recently several authors developed more exact methods for the calculation of the GS I value (see e.g. [14 17]), nevertheless without error estimation. Moreover, the various input (in situ measured) parameters for determining the $G S I$ value depend on the site investigators (see e.g. [18]). The subjectivity of the results is well-known, thus the differences for the same tunnel face can reach as much as $30 \%$.

According to the definition of GSI, the surface quality and the structure of the rock mass have a similar effect upon the mechanical properties. E.g. GS I value is 70 both in case of massive rock mass with few widely spaced but smooth and moderately weathered discontinuities (point " $A$ " in Fig. 1) and a very blocky, partially disturbed rock mass with very rough and fresh surfaces of discontinuities (point " $\mathrm{B}$ " in Fig. 1). It is easy to realize that probably the rock mass behavior is different in these two cases, however, according to the Hoek-Brown failure theory, it should be the same.

The influence of blast damage on the near surface rock mass properties has been taken into account in the 2002 version of the Hoek-Brown criterion [19]. A disturbance parameter $D$ has been introduced, which characterizes the degree of disturbance due to blast damage and stress relaxation. It varies from 0 for undisturbed in situ rock masses to 1 for very disturbed rock masses. The exact determination of the disturbance factor $D$ is difficult, there are no guidelines except the Table 11 [19]. According to that paper, $10-20 \%$ errors are tolerable. E.g. both the good blasting $(D=0.7)$ and poor blasting $(D=0.9)$ enable a value $D=0.8 \pm 0.1$ with a $12.5 \%$ uncertainty in $D$.

\section{Mechanical equations based on $G S I$ and $D$ values}

\subsection{Hoek-Brown failure envelop}

The Hoek-Brown equation is one of the most popular failure criteria for determining the failure envelope of the rock mass. For jointed rock masses it is given by the following generalized formula [18] and recently it is ISRM suggestion, as well [20]:

$$
\sigma_{1}^{\prime}=\sigma_{3}^{\prime}+\sigma_{c i}\left(m_{b} \frac{\sigma_{3}^{\prime}}{\sigma_{c i}}+s\right)^{a},
$$

where

- $\sigma_{1}^{\prime}$ and $\sigma_{3}{ }^{\prime}$ are the maximum and minimum effective principal stresses at failure;

- $\sigma_{c i}$ is the uniaxial compressive strength of the intact rock sections;

- $m_{b}$ is the value of the Hoek-Brown constant for the rock mass, depending on the Hoek-Brown constant of the intact rock $\left(m_{i}\right)$, the Geological Strength Index $(G S I)$ and the blast disturbance $(D)$ :

$$
m_{b}=m_{i} \exp \left(\frac{G S I-100}{28-14 D}\right)
$$

- $s$ and $a$ are parameters that also depend on the rock mass characteristics:

$$
s=\exp \left(\frac{G S I-100}{9-3 D}\right)
$$

and

$$
a=\frac{1}{2}+\frac{1}{6}\left(e^{-G S I / 15}-e^{-20 / 3}\right) .
$$

According to the Hoek-Brown equation Eq. (1), the ratio of the uniaxial compressive strength of the rock mass $\left(\sigma_{\mathrm{cm}}\right)$ to that of the intact rock $\left(\sigma_{c i}\right)$ is given by:

$$
\sigma_{c m} / \sigma_{c i}=s^{a}
$$

where $s$ and $a$ can be calculated by Eqs. (3) and (4), respectively.

\subsection{Deformation modulus of rock mass}

The introduced formula of Hoek and Diederichs [21] calculates the deformation modulus from the $G S I$ value and $D$ factor as:

$$
E_{r m}(M P a)=100.000 \frac{1-D / 2}{1+e^{(75+25 D-G S I) / 11}}
$$

or if the deformation modulus of the intact rock $\left(E_{i}\right)$ is known, Eq. (1) can be modified to:

$$
E_{r m}(M P a)=E_{i}\left(0.02+\frac{1-D / 2}{1+e^{(60+15 D-G S I) / 11}}\right)
$$

Using these two formulas the estimated deformation moduli are not the same, they depend on the deformation modulus of the intact rock - the ratio of the two results in case of low GSI values can be large. 


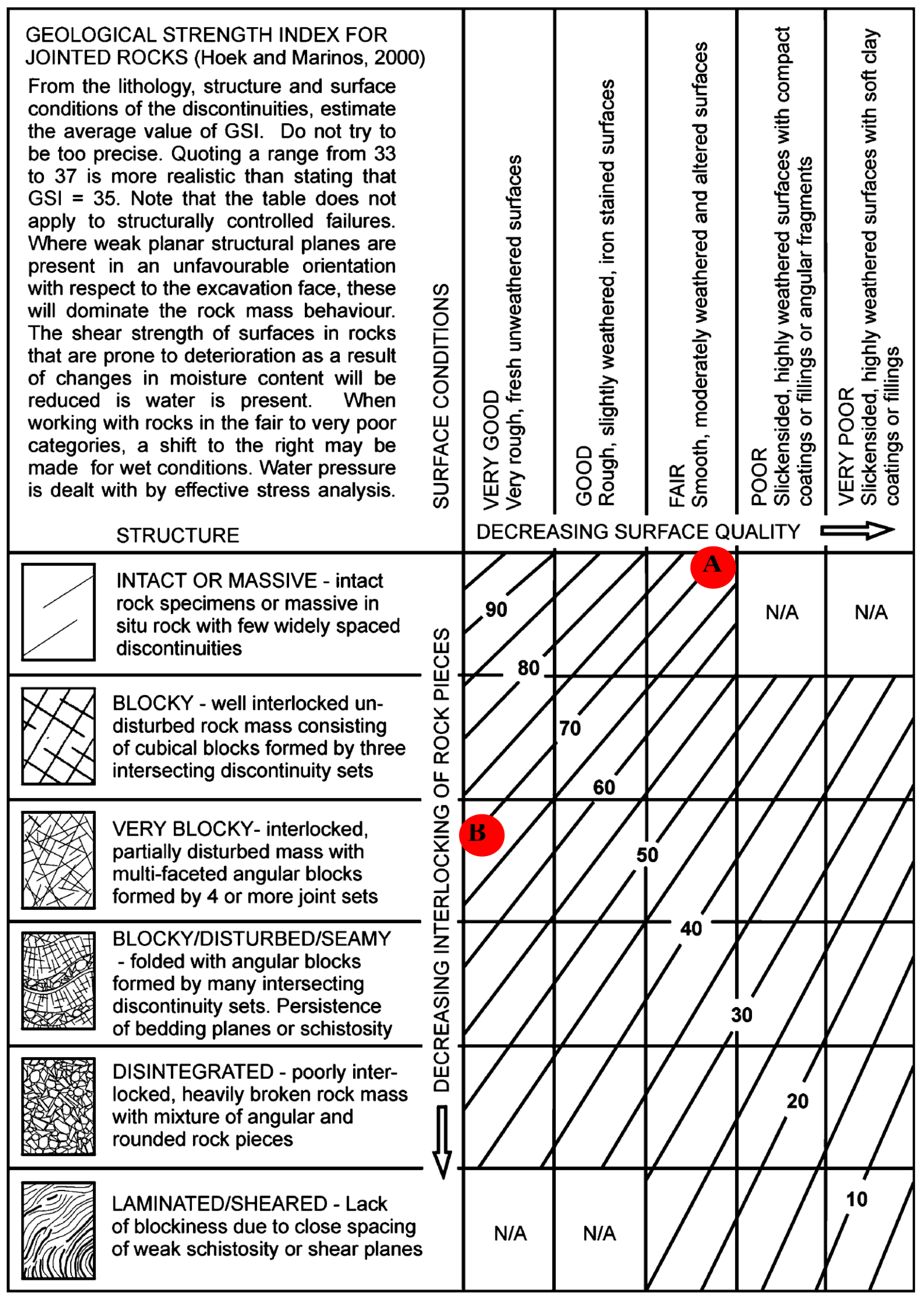

Fig. 1. General chart for $G S I$ [10]. 
Tab. 1. Guidelines for estimating disturbance factor $D[\overline{19}$

\begin{tabular}{|c|c|c|}
\hline Appearance of rock mass & Description of rock mass & Suggested value of D \\
\hline & $\begin{array}{l}\text { Excellent quality controlled blasting or } \\
\text { excavation by Tunnel Boring Machine results } \\
\text { in minimal disturbance to the confined rock } \\
\text { mass surrounding a tunnel. }\end{array}$ & $\mathrm{D}=0$ \\
\hline & $\begin{array}{l}\text { Mechanical or hand excavation in poor quality } \\
\text { rock masses (no blasting) results in minimal } \\
\text { disturbance to the surrounding rock mass. } \\
\text { Where squeezing problems result in significant } \\
\text { floor heave, disturbance can be severe unless a } \\
\text { temporary invert, as shown in the photograph, } \\
\text { is placed. }\end{array}$ & $\begin{array}{l}\mathrm{D}=0 \\
\mathrm{D}=0.5 \\
\text { No invert }\end{array}$ \\
\hline & $\begin{array}{l}\text { Very poor quality blasting in a hard rock tunnel } \\
\text { results in severe local damage, extending } 2 \text { or } 3 \\
\mathrm{~m} \text {, in the surrounding rock mass. }\end{array}$ & $\mathrm{D}=0.8$ \\
\hline & $\begin{array}{l}\text { Small scale blasting in civil engineering slopes } \\
\text { results in modest rock mass damage, } \\
\text { particularly if controlled blasting is used as } \\
\text { shown on the left hand side of the photograph. } \\
\text { However, stress relief results in some } \\
\text { disturbance. }\end{array}$ & $\begin{array}{l}\mathrm{D}=0.7 \\
\text { Good blasting } \\
\mathrm{D}=1.0 \\
\text { Poor blasting }\end{array}$ \\
\hline & $\begin{array}{l}\text { Very large open pit mine slopes suffer } \\
\text { significant disturbance due to heavy production } \\
\text { blasting and also due to stress relief from } \\
\text { overburden removal. } \\
\text { In some softer rocks excavation can be carried } \\
\text { out by ripping and dozing and the degree of } \\
\text { damage to the slopes is less. }\end{array}$ & $\begin{array}{l}\mathrm{D}=1.0 \\
\text { Production blasting } \\
\mathrm{D}=0.7 \\
\text { Mechanical excavation }\end{array}$ \\
\hline
\end{tabular}




\section{Sensitivity analysis}

The sensitivity of a function $f$ regarding the uncertainties of the variables can be characterized by the formula commonly known as propagation of uncertainty or propagation of error [22]. Let us suppose that $f$ is a real function which depends on $n$ random and independent variables $x_{1}, x_{2}, \ldots x_{n}$. From their uncertainties $\Delta x_{1}, \Delta x_{2}, \ldots \Delta x_{n}$ we can calculate the uncertainty $\Delta f$ of $f$ :

$$
\Delta f=\left(\sum_{i=1}^{n}\left(\left.\frac{\partial f}{\partial x_{i}}\right|_{x_{1}, \ldots, x_{i-1}, x_{i+1}, \ldots, x_{n}} \Delta x_{i}\right)^{2}\right)^{\frac{1}{2}} .
$$

Here it is assumed that the variables are uncorrelated and the underlying probability distribution of the errors is Gaussian.

Therefore if the variables $x_{i}$ are measured with an experimental error, $x_{i} \pm \Delta x_{i}$, we can estimate the uncertainty of their arbitrary function with the above formula. This formula is robust; the Gaussian distribution is a reasonable assumption in most cases.

This formula is an approximation from two different points of view in our case. The variables of the formula, GSI and $D$, are not necessarily independent. Considering the measurement methods of $D$ and GSI (see Fig. 1), the quantification of this correlation does not seem to be easy, but it can only increase the uncertainty. The second point is that, for both our variables, the domain is a finite interval. In this case the normal distribution is a bad approximation near the ends of the intervals. A slightly better approximation could be given e.g. by the Euler-Gamma distribution.

In this paper, the relative sensitivity of the Hoek-Brown parameters and the rock mass strength have been calculated for the case of $10 \%$ relative uncertainties for three representative values of the parameter $D$, that is, when $D \pm 0.1 D$ and $G S I \pm 0.1 G S I$ for $D=0.1 ; 0.5$ and 0.9 .

\section{Results of the sensitivity analyses}

\subsection{Analysis of the Hoek-Brown failure envelope}

\section{- Analysis of the sensitivity of the $m_{b}$ value}

The effect of $10 \%$ deviation in the GSI value was calculated and presented in Fig. 2 We can see that the relative sensitivity of $m_{b}$ is at least double the uncertainties of the $G S I$ and $D$ values, and may be 7 times higher in case of large disturbance parameters and low and high GSI values.

\section{- Analysis of the sensitivity of $s$}

Fig. 3 shows that the relative sensitivity of the parameter $s$ is at least the triple of the uncertainties of the variables, and may even be 15 times higher (!) in case of large disturbance parameters and high $G S I$ values.

\section{- Analysis of the sensitivity of the a parameter}

The parameter $a$ is independent of the disturbance factor and not sensitive to the uncertainties in GSI (Eq. (4)). The maximum relative sensitivity of $s$ is about equal to the uncertainty of

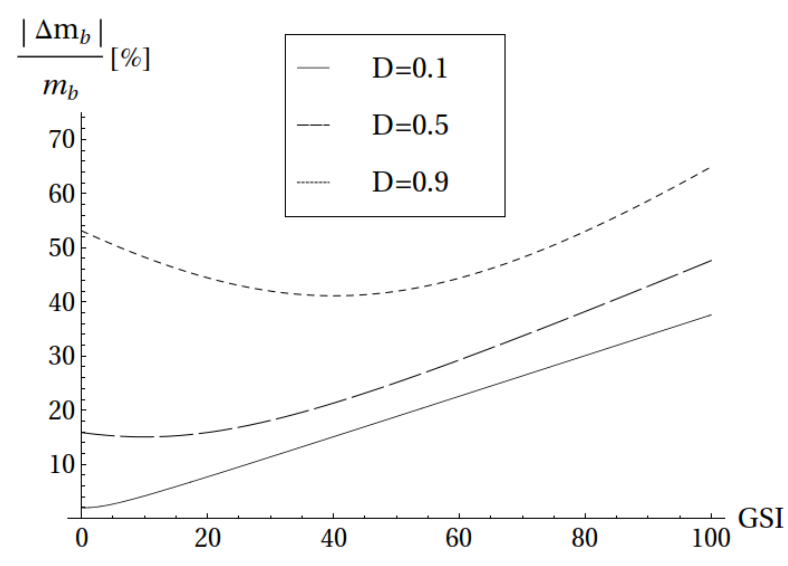

Fig. 2. The relative sensitivity of $m_{b}$ in case of $10 \%$ measurement errors $(G S I \pm 0.1 G S I$ and $D \pm 0.1 D)$.

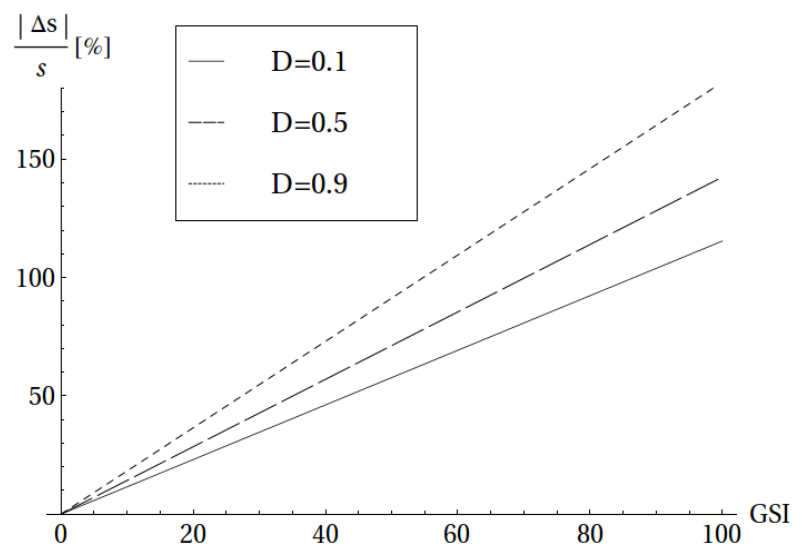

Fig. 3. The relative sensitivity of $s$ in case of $10 \%$ measurement errors $(G S I \pm 0.1 G S I$ and $D \pm 0.1 D)$.

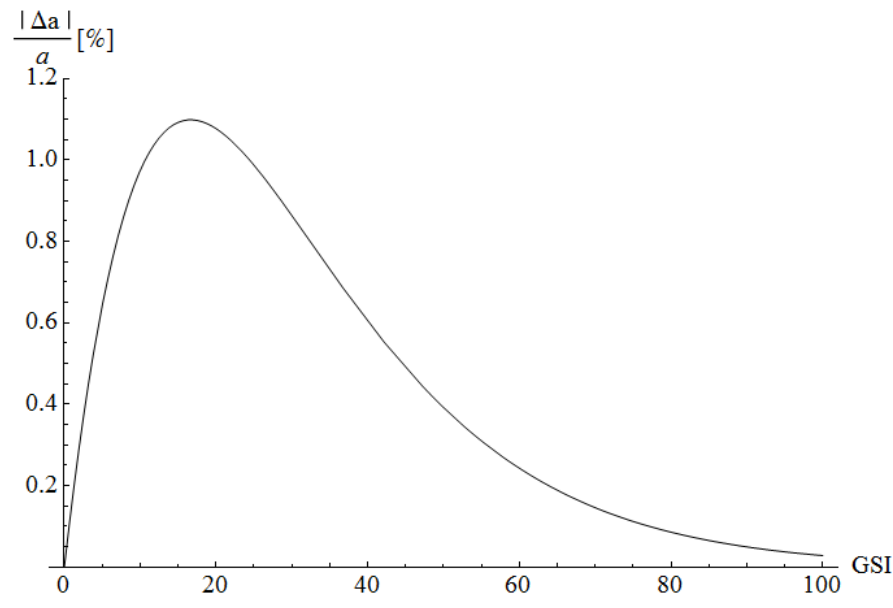

Fig. 4. The relative sensitivity of $a$ in case of $10 \%$ measurement errors $(G S I \pm 0.1 G S I)$. 
the variables at $G S I$ value 20. The relative sensitivity of $a$ in the case $10 \%$ measurement error is plotted in Fig. 4

\section{- Analysis of the sensitivity of the strength of the rock mass}

The dependence of GSI on the rock mass strength $\sigma_{1}$ (see Eq. (1)) in the case of various disturbance factors $D$ is presented in Fig. 6 According to Figs. 5, 6 at low GSI values the uncertainty in the disturbance parameter $D$ determines the sensitivity of the rock mass strength, while at high GSI values the uncertainty in GSI dominates and the disturbance parameters has less influence. Fig. 7 shows that the relative sensitivity of the rock mass strength $\sigma_{1}$ is at least the double of the uncertainties in the GS I and the disturbance parameters, and may be 8 times higher in case of large disturbance parameter and high GSI values.

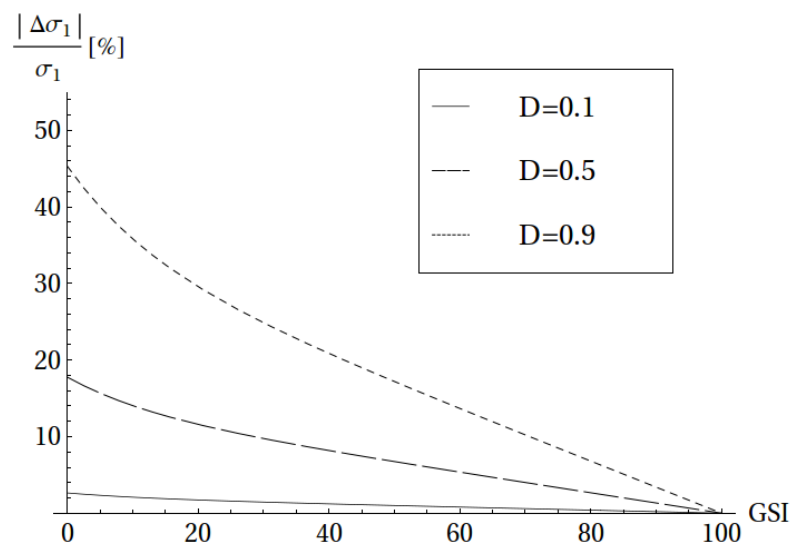

Fig. 5. The relative sensitivity of the rock mass strength $\sigma_{1}$ in case of $10 \%$ measurement error in the disturbance parameter and exact GSI values $(D \pm 0.1 D)$.

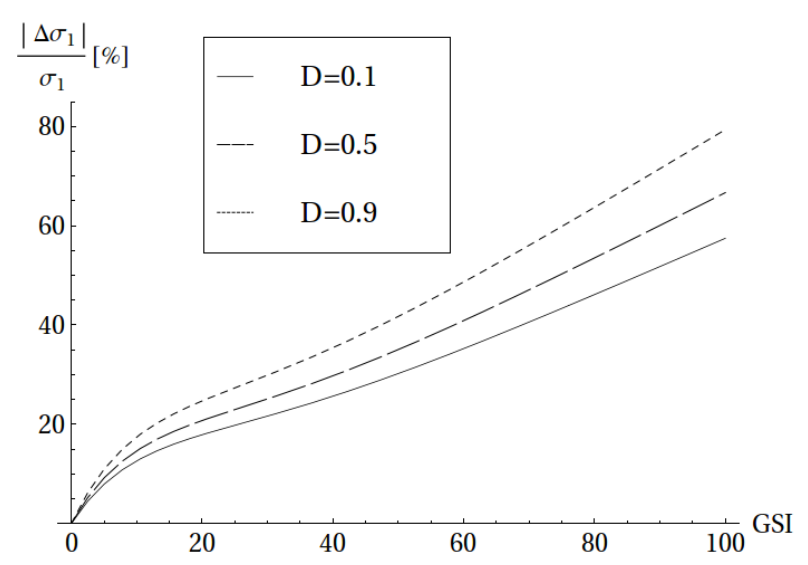

Fig. 6. The relative sensitivity of the rock mass strength $\sigma_{1}$ in case of $10 \%$ measurement error in the $G S I$ and exact disturbance parameter determination $(G S I \pm 0.1 G S I)$.

The sensitivity of the Hoek-Brown criteria as a function of both $G S I$ and disturbance parameter is plotted in Fig. 8 in case of $10 \%$ errors (i.e.: $G S I \pm 0.1 G S I$ and $D \pm 0.1 D$ ).

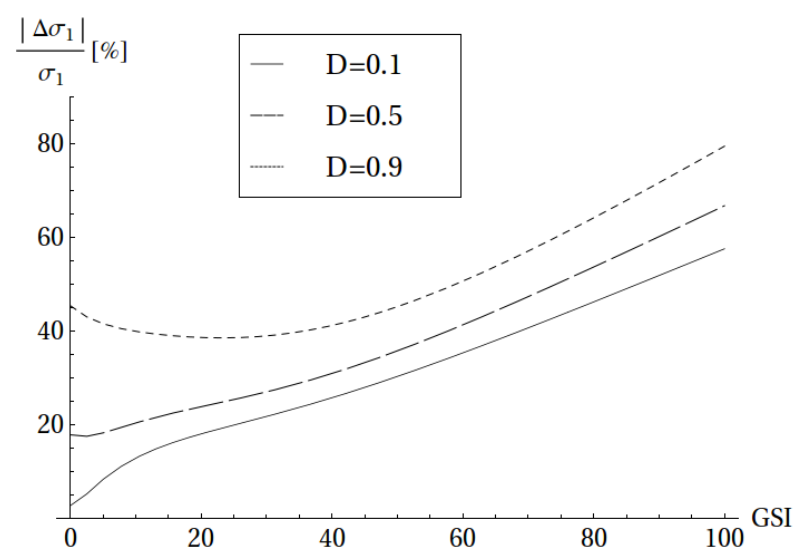

Fig. 7. The relative sensitivity of the rock mass strength $\sigma_{1}$ in case of $10 \%$ measurement errors $(G S I \pm 0.1 G S I$ and $D \pm 0.1 D)$.

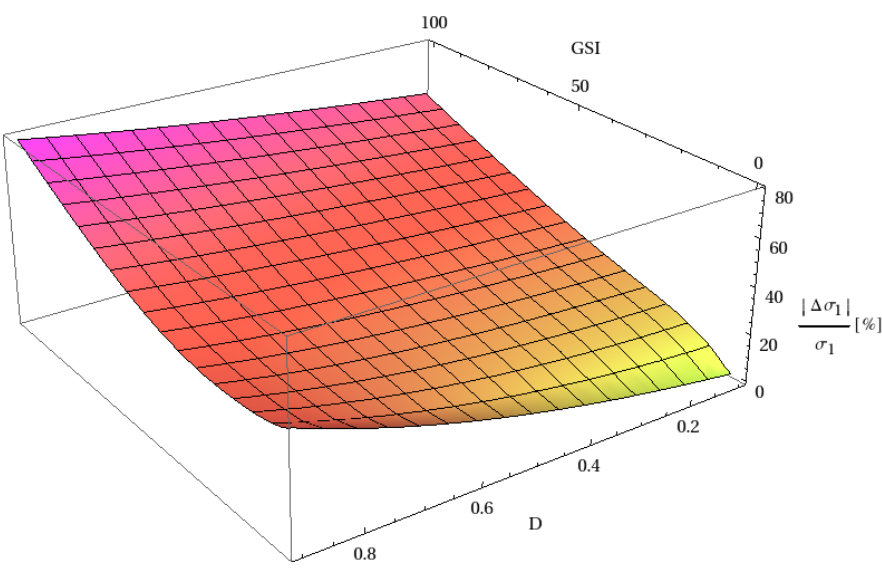

Fig. 8. The sensitivity of the Hoek-Brown failre criteria in case of $10 \%$ errors $(G S I \pm 0.1 G S I$ and $D \pm 0.1 D)$.

\subsection{Analysis the deformation moduli of rock mass}

The sensitivity of various empirical formulas to parameter uncertainty is an important factor for a designer. To establish good empirical formulas, one should have some sense on the effect of variations in the input parameters to judge the acceptability of the design. In this note, we analyze the above formulas from this point of view, giving some practical tools to enable rapid sensitivity analyses.

In estimating the sensitivity, we have assumed that the variables are uncorrelated, therefore, one can apply Eq. (7). If the uncertainty in the disturbance factor $D$ is $\Delta D$ and in the $G S I$ it is $\triangle G S I$, one can find:

$$
\begin{aligned}
& \Delta E_{r m}(M P a)= \\
& =\sqrt{\left(\frac{1}{11(1+A)} \Delta G S I\right)^{2}+\left(\left(\frac{1}{D-2}-\frac{25}{11(1+A)}\right) \Delta D\right)^{2}}
\end{aligned}
$$

where $A=e^{(G S I-75-25 D) / 11}$

The relative sensitivity for the simple Hoek-Diederichs criteria of Eq. (6) is plotted in the case of $\Delta D=0.05$ and $\Delta G S I / G S I=0.05$ in Fig. 9 for disturbance values $D=0,0.5$ and 1 . One can see that the sensitivity in the rock mass modu- 
lus is between $15-35 \%$ and strongly depends on the $G S I$ value. There is a peak in the sensitivity between $G S I$ values 60 and 80. Fig. 10 shows the corresponding absolute sensitivity according to Eq. (8). The Gauss's law applied to the modified Hoek-Diederichs criteria (Eq. (7)) gives

$$
\begin{aligned}
& \Delta E_{r m}(M P a)=\left(1-\frac{0.02 E_{i}}{E_{r m}}\right) x . \\
& \cdot \sqrt{\left(\frac{1}{11(1+A)} \Delta G S I\right)^{2}+\left(\left(\frac{1}{D-2}-\frac{15}{11(1+A)}\right) \Delta D\right)^{2}}
\end{aligned}
$$

where $A=e^{(G S I-60-15 D) / 11}$.

The relative sensitivity estimated by Eq. (9) is plotted for $\Delta D=0.05$ and $\Delta G S I / G S I=0.05$ in Fig. 11 for values of $D=0.0,0.5$ and 1.0. The sensitivity in the rock mass modulus is between $0.5-22 \%$ and, again, it strongly depends on the GSI value. The peaked property is even more apparent in this case, with the greatest sensitivity occurring for GS I values between 40 and 60. Fig. 12 shows the corresponding absolute sensitivity according to Eq. (10).

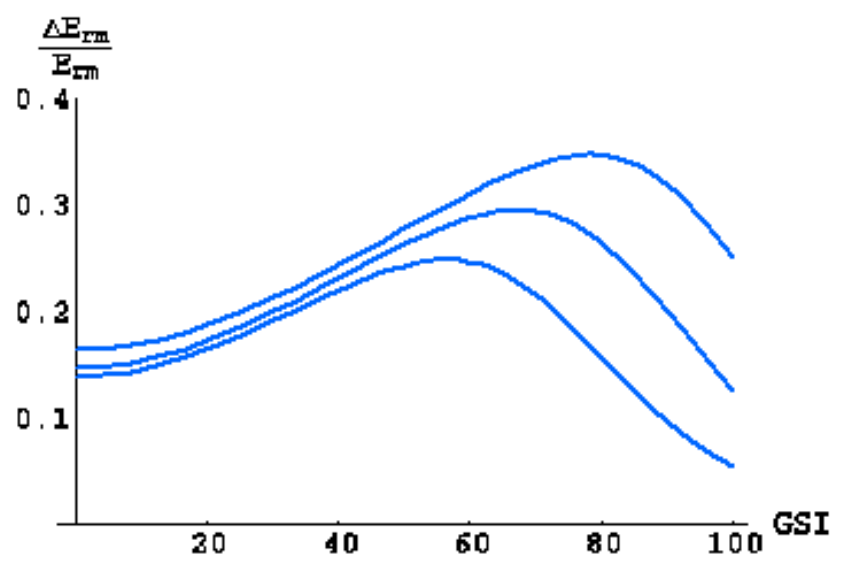

Fig. 9. Relative sensitivity of the simple Hoek-Diederichs function (Eq. (1)) as a function $G S I$, in case $\Delta D=0.05, \Delta G S I / G S I=0.05$ if $D=0,0.5$ and 1 (from below).

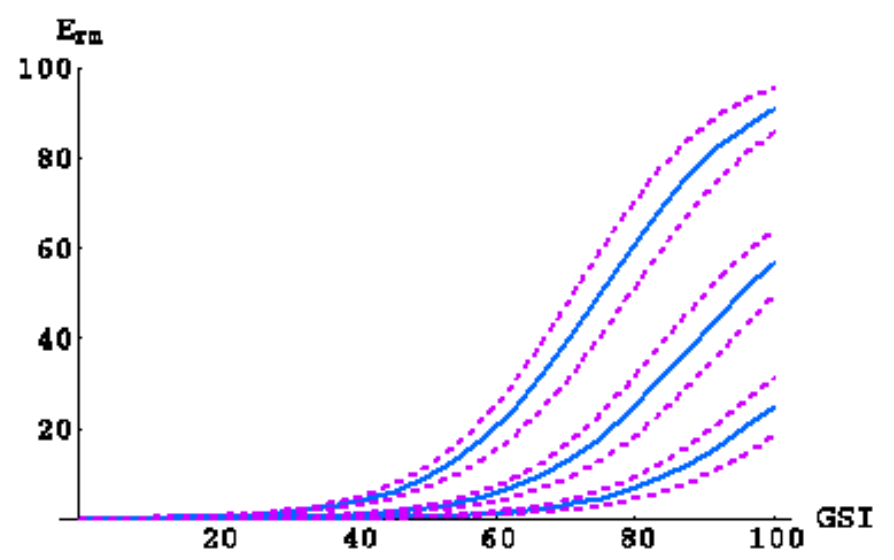

Fig. 10. Absolute sensitivity of the simple Hoek-Diederichs function (Eq. (1)) as a function $G S I$, in case $\Delta D=0.05, \Delta G S I / G S I=0.05$ if $D=0,0.5$ and 1 (from below). The dashed lines around the solid ones denote the sensitivity intervals.

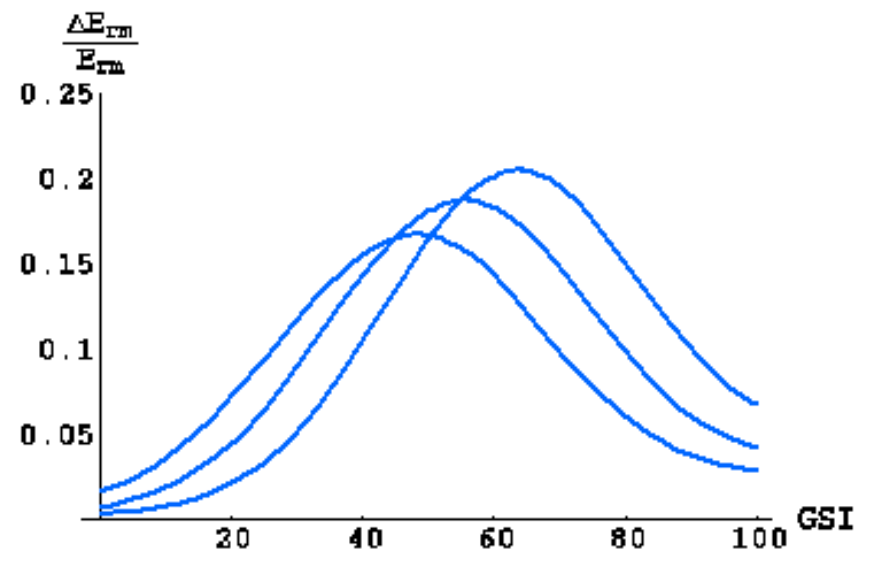

Fig. 11. Relative sensitivity of the modified Hoek-Diederichs equation (Eq. 2) as a function $G S I$, in case $\Delta D=0.1$ and $\Delta G S I=0$ if $D=0,0.5$ and 1 (from below at left).

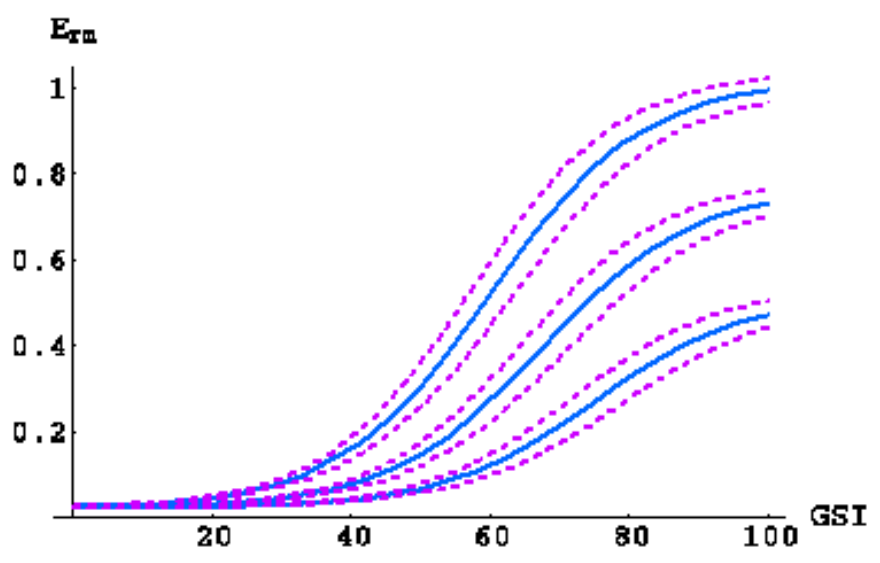

Fig. 12. Absolute sensitivity of the modified Hoek-Diederichs equation (Eq. (2)) as a function $G S I$, in case $\Delta D=0.05, \Delta G S I / G S I=0.05$ if $D=0,0.5$ and 1 (from below). The dashed lines around the solid ones denote the sensitivity intervals.

\section{Conclusion}

The sophisticated empirical Hoek-Brown formula is sensitive to the uncertainties of the Geological Strength Index $(G S I)$ and disturbance parameter $(D)$ values. Its relative sensitivity may reach a value 8 times higher than the relative uncertainties of the $G S I$ and $D$ factors in the case of high disturbance and $G S I$ values, if these relative uncertainties are uniform. With more exact measurements/determination of GS I values and disturbance factor determination at low GSI values, the relative uncertainty of the Hoek-Brown formula can be considerably reduced.

According to our analysis, the Hoek-Brown (H-B) failure criteria can be highly sensitive to the uncertainties in the GSI and disturbance parameters. This sensitivity is due to the complex structure of the function, criteria containing a lower number of parameters may be less sensitive. In any case the rock engineering design should consider the uncertainties of the design parameters and calculate them routinely.

Using the Hoek-Diederichs (H-D) equations, the rock mass deformation modulus can be determined if the GSI and $D$ are known. The determination of each parameter is subjective, and hence, to know the sensitivity of these equations is very important. Using the Gauss's formula, the sensitivity of the equations 
was analyzed for $\Delta D=0.05$ and $\Delta G S I / G S I=0.05$ for $D=0,0.5$ and 1. It was shown that, in case of the simple H-D equation, the uncertainty in the rock mass modulus is between $15-35 \%$ while for the modified H-D equation it is between $0.5-22 \%$. In both cases, the sensitivity strongly depends on the GSI value.

Our analysis points out the relative importance of the different parts of the formula from this point of view. According to these results, using the GSI system without any control is not recommended.

Finally, let us summarize the problematic aspects of $G S I$ and $D$ based rock failure criteria:

- the GS I value cannot be determined exactly,

- the $D$ value is not defined and not possible to measure,

- the continuous variation of $D$ in rock mass is not considered,

- the block size is not defined,

- it is false that the rock mass behavior depends on the structure of the rock mass in a similar manner than on the surface quality,

- due to the sensitivity of the suggested equations, their application increases the risk of the construction.

\section{Acknowledgements}

P. Ván acknowledges the financial support of grants OTKA K81161, K104260 and TT 10-1-2011-0061/ZA-15-2009 for this research.

\section{References}

1 Bieniawski R, Misconceptions in the applications of rock mass classification and their corrections, 2011, www.geocontrol.es pp. 1-32. ADIF Seminar on Advanced Geotechnical Characterization for Tunnel Design Madrid, Spain.

2 Malkowski P, Application of studies in mines and laboratories for selection of the constants in the Hoek-Brown criterion, 2010. Achiwum Gornictwa, from Bieniawski [1].

3 Anagnostou G, Pimentel E, $Z u$ den Felsklassifikationen mit Indexwerten im Tunnelbau, Geotechnik, 35(2), (2012), 83-93, DOI doi:10.1002/gete.201100022

4 Ván P, Vásárhelyi B, Sensitivity analysis of the Hoek-Diederichs rock mass modulus estimating formula, In: Soussa LR;O C.; Grossmann (ed.), Proc. 11. ISRM Cong. Lisboa, "The Second Half Century of Rock Mechanics", 2007, pp. 411-414.

5 Ván P, Vásárhelyi B, Sensitivity analysis of the generalized Hoek-Brown failure criterion, In: Kwasnievski; Lydzba (ed.), Proc. Eurock2013, "Rock Mechanics for Resources", 2013, pp. 835-840.

6 Hoek E, Wood D, Shah S, A modified Hoek-Brown criterion for jointed rock masses, In: Hudson J (ed.), Rock Characterization: ISRM Symp, Eurock '92, 1992, pp. 209-213.

7 Hoek E, Kaiser P, Bawden W, Support of Underground Excavations in Hard Rock, Balkema; Rotterdam, 1995.

8 Hoek E, Brown E, Practical estimates or rock mass strength, Int. J. Rock Mech. Min. Sci., 34(8), (1997), 1165-1186, DOI 10.1016/S13651609(97)80069-X

9 Görög P, Vámos M, Török Á, Vásárhelyi B, A Geológiai Szilárdsági Index (GSI) magyarországi alkalmazhatósága. (The Geological Strength Index and its application in Hungary), Földtani Közlöny, 140(1), (2010), 89-96.
10 Marinos V, Marinos P, Hoek E, The Geological Strength Index: Applications and Limitations, Bull. Engng. Geol. Env., 64(1), (2005), 55-65, DOI 10.1007/s10064-004-0270-5

11 Marinos P, Hoek E, A geologically friendly tool for rock mass strength estimation, In: Proc. GeoEng2000 Conference, 2000, pp. 1422-1442.

12 Marinos P, Hoek E, Estimating the geotechnical properties of heterogeneous rock masses such as flysch, Bull. Engng. Geol. Env., 60(2), (2001), 85-92, DOI 10.1007/s100640000090

13 Shen B, Barton N, The disturbed zone around tunnels in jointed rock masses, Int. J. Rock Mech. Min. Sci., 34(1), (1997), 117-125, DOI 10.1016/S1365-1609(97)80037-8

14 Sonmez H, Urusay R, Modifications to the geological strength index (GSI) and their applicability to stability of slopes, Int. J. Rock Mech. Min. Sci., 36(6), (1999), 743-760, DOI 10.1016/S0148-9062(99)00043-1

15 Cai M, Kaiser P, Uno H, Tasaka Y, Minami M, Estimation of rock mass deformation modulus and strength of jointed hard rock masses using GSI system, Int. J. Rock Mech. Min. Sci., 41(1), (2004), 3-19, DOI 10.1016/S13651609(03)00025-X

16 Russo G, A new rational method for calculating the GSI, Tunneling \& Underground Space Techn., 24(1), (2009), 103-111, DOI 10.1016/j.tust.2008.03.002

17 Hoek E, Carter T, Diederichs M, Quantification of the Geological Strength Index chart, In: Proc. 47th US Rock Mech./Geomechanics Symp., 2013, pp. 1-8.

18 Deák F, Kovács L, Vásárhelyi B, Comparison of Different Rock Mass Classifications at Bátaapáti Radioactive Waste Repository, In: Proc. Eurock 2012, 2012, pp. 1-8.

19 Hoek E, Carranza-Torres C, Corkum B, Hoek-Brown failure criterion 2002 Edition, In: Hammah R (ed.), Proc. 5. North American Rock Mech. Conf., 2002, pp. 267-271.

20 Eberhard E, The Hoek-Brown failure criterion, Rock Mech. Rock Eng., 45(6), (2012), 981-988, DOI 10.1007/s00603-012-0276-4

21 Hoek E, Diederichs M, Empirical estimation of rock mass modulus, Int. J. Rock Mech. Min. Sci., 43(2), (2006), 203-215, DOI 10.1016/j.ijrmms.2005.06.005

22 Bronstein I, Semendjajew K, Handbook of Mathematics, Springer; Berlin, 2004. 